\title{
Early Life Stress Alters Adult Serotonin 2C Receptor Pre-mRNA Editing and Expression of the $\alpha$ Subunit of the Heterotrimeric G-Protein Gq
}

\author{
Punita Bhansali, ${ }^{1,3}$ Jane Dunning, ${ }^{3}$ Sarah E. Singer, ${ }^{2}$ Leora David, ${ }^{1,3}$ and Claudia Schmauss ${ }^{1,3}$ \\ ${ }^{1}$ Department of Psychiatry and ${ }^{2}$ Center for Neurobiology and Behavior, Columbia University, and ${ }^{3}$ Department of Neuroscience, New York State Psychiatric \\ Institute, New York, New York 10032
}

\begin{abstract}
Infant maternal separation, a paradigm of early life stress in rodents, elicits long-lasting changes in gene expression that persist into adulthood. In BALB/c mice, an inbred strain with spontaneously elevated anxiety and stress reactivity, infant maternal separation led to increased depression-like behavioral responses to adult stress and robustly increased editing of serotonin $2 \mathrm{C}$ receptor pre-mRNA. Chronic fluoxetine treatment of adult BALB/c mice exposed to early life stress affected neither their behavioral responses to stress nor their basal 5- $\mathrm{HT}_{2 \mathrm{C}}$ pre-mRNA editing phenotype. However, when fluoxetine was administered during adolescence, depression-like behavioral responses to stress were significantly diminished in these mice, and their basal and stress-induced 5-HT $2 \mathrm{C}$ pre-mRNA editing phenotypes were significantly lower. Moreover, when BALB/c mice exposed to early life stress were raised in an enriched postweaning environment, their depression-like behavioral responses to adult stress were also significantly diminished. However, their 5 -HT $2 \mathrm{C}$ premRNA editing phenotype remained unaltered. Hence, the similar behavioral effects of enrichment and fluoxetine treatment during adolescence were not accompanied by similar changes in 5- $\mathrm{HT}_{2 \mathrm{C}}$ pre-mRNA editing. Enriched and nonenriched BALB/c mice exposed to early life stress also exhibited significantly increased expression of mRNA and protein encoding the G $\alpha \mathrm{q}$ subunit of G-protein that couples to 5- $\mathrm{HT}_{2 \mathrm{~A} / 2 \mathrm{C}}$ receptors. In contrast, $\mathrm{G} \alpha \mathrm{q}$ expression levels were significantly lower in fluoxetine-treated mice. These findings

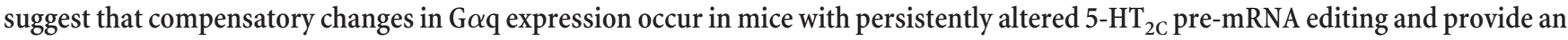
explanation for the dissociation between $5-\mathrm{HT}_{2 \mathrm{C}}$ receptor editing phenotypes and behavioral stress responses.
\end{abstract}

Key words: early life stress; serotonin 2C receptor; RNA editing; G-protein; antidepressant drugs; environmental enrichment

\section{Introduction}

In subjects with a genetic predisposition, early life trauma is a prominent risk factor for adult-onset depression. Adverse early life events lead to abnormalities in several brain functions that persist into adulthood and are often also resistant to adult treatment with antidepressant drugs (Caspi et al., 2003; Penza et al., 2003; Nemeroff et al., 2003; Kendler et al., 2004; Holmes et al., 2005).

Genetically distinct strains of mice that exhibit substantial differences in anxiety, stress reactivity, brain tissue levels of serotonin, and responsiveness to antidepressant treatment are suitable animal models for studies on the role of genetic and environmental factors in determining the impact of early life stress on the development of adult depression-like behavior. For example, in contrast to the resilient strain $\mathrm{C} 57 \mathrm{BL} / 6, \mathrm{BALB} / \mathrm{c}$ mice have lower forebrain serotonin levels (Zhang et al., 2004), exhibit spontaneously elevated anxiety and stress reactivity (Belzung and Griebel,

Received Aug. 4, 2006; revised Dec. 4, 2006; accepted Jan. 2, 2007

This work was supported by National Institutes of Health Grants MH061906 and MH062185.

Correspondence should be addressed to Dr. Claudia Schmauss, Department of Psychiatry and Neuroscience, Columbia University and New York State Psychiatric Institute, 1051 Riverside Drive, New York, NY 10032. E-mail: schmauss@neuron.cpmc.columbia.edu.

DOI:10.1523/JNEUROSCI.4632-06.2007

Copyright $\odot 2007$ Society for Neuroscience $\quad$ 0270-6474/07/271467-07\$15.00/0
2001; Tang et al., 2002), and show increased responsiveness to chronic, but not acute, antidepressant treatment (Dulawa et al., 2004). They also differ in their basal and adult stress-induced expression of serotonin $2 \mathrm{C}\left(5-\mathrm{HT}_{2 \mathrm{C}}\right)$ receptor mRNA isoforms (Englander et al., 2005) that result from pre-mRNA editing via base modification of adenosine to inosine (Burns et al., 1997). In $5-\mathrm{HT}_{2 \mathrm{C}}$ pre-mRNA, five exonic adenosines (named A, B, C', C, and $\mathrm{D}$ editing sites) can be converted to inosine to alter the coding potential of three triplet codons, and distinctly edited isoforms encode receptors with decreased constitutive activity and decreased agonist-stimulated activation of $\mathrm{G} \alpha \mathrm{q}$ protein (Niswender et al., 1999; Wang et al., 2000). Because $5-\mathrm{HT}_{2 \mathrm{C}}$ receptors are thought to play a role in the regulation of mood (Roth et al., 1998), it is of interest to note that significantly increased editing of 5- $\mathrm{HT}_{2 \mathrm{C}}$ pre-mRNA was found in the prefrontal cortex of suicide victims with a history of major depression (Gurevich et al., 2002a), a disease in which a genetic predisposition and early life trauma are significant components of the underlying psychopathology (Caspi et al., 2003).

To test the effect of adverse early life events on the expression of the adult 5- $\mathrm{HT}_{2 \mathrm{C}}$ pre-mRNA editing phenotype, we exposed $\mathrm{BALB} / \mathrm{c}$ to infant maternal separation (IMS), a powerful paradigm of early life stress in rodents that elicits adult depressionlike behaviors (Plotsky and Meaney, 1993). We found that adult 
mice exposed to IMS exhibit increased passive behavioral responses to stress that are resistant to antidepressant treatment with fluoxetine during adulthood. They also exhibit increased $5-\mathrm{HT}_{2 \mathrm{C}}$ pre-mRNA editing and increased $\mathrm{G} \alpha \mathrm{q}$ expression in forebrain neocortex. In addition, although adolescent fluoxetine treatment and environmental enrichment both diminished behavioral responses to adult stress in these mice, only fluoxetine treatment altered the $5-\mathrm{HT}_{2 \mathrm{C}}$ pre-mRNA editing phenotype and significantly lowered the increased expression of $\mathrm{G} \alpha \mathrm{q}$ that resulted from early life stress. Our findings suggest that, in mice exposed to early life stress, increased $5-\mathrm{HT}_{2 \mathrm{C}}$ pre-mRNA editing that leads to mRNA isoforms encoding receptors with reduced sensitivity to serotonin elicits either a compensatory increase in $\mathrm{G} \alpha \mathrm{q}$ expression or, alternatively, that increased G $\alpha \mathrm{q}$ activation increases $5-\mathrm{HT}_{2 \mathrm{C}}$ pre-mRNA editing.

\section{Materials and Methods}

Animals. All experiments involving animals were approved by the Institutional Animal Care and Use Committee of Columbia University. $\mathrm{BALB} / \mathrm{cJ}$ mice were housed in a facility with a $12 \mathrm{~h}$ light/dark cycle with lights on at 6:00 A.M. and were given food and water ad libitum.

IMS. Maternal separation of pups from their dam was conducted daily between 1:00 and 4:00 P.M., starting at postnatal day 2 (P2) and terminating at P15 (IMS animals). All dams were first-time mothers, and only litters of six to eight animals were used in this study. First, the dam was removed from the home cage and placed into a clean cage. Then, pups were collected and placed into another clean cage. After the $180 \mathrm{~min}$ separation, pups and dams were returned to their home cage. Control animals were standard facility-reared offspring of first-time mothers (SFR animals). For both SFR and IMS animals, the first cage change occurred $2 \mathrm{~d}$ after birth of pups, and cages were then changed every fourth day. SFR animals did not receive extra handling, and none of the SFR and IMS pups were culled and sexed after birth to keep handling of all animals to a minimum.

For all experiments on IMS and SFR mice, a total of 12 litters per group were used. At the time of weaning at P28, animals were randomly selected from different litters so that three to four animals per cage were derived from three to four different litters. These cages were then assigned to one of three different treatment conditions in which mice were either raised to adulthood without postweaning or adult treatment, treated with fluoxetine between P60 and P88, or treated with fluoxetine between P32 and P61.

Postweaning enrichment. In additional experiments, IMS and SFR animals were weaned at P28 and then raised in an enriched environment. A major component of this enrichment was cross-housing of $\mathrm{BALB} / \mathrm{c}$ mice with the stress-resistant C57BL/6 mice. These experiments were motivated by a pilot study by Holmes et al. (2005), which showed that crosshousing juvenile mice of two inbred strains that differ markedly in their emotionality (AJ and C57BL/6 mice) reversed the heightened anxietylike phenotype of AJ mice in the free exploration tests but left the behavior of $\mathrm{C} 57 \mathrm{BL} / 6$ cross-housed with $\mathrm{AJ}$ mice unaltered. Hence, in our experiments, IMS BALB/c mice were group housed with age- and sexmatched C57BL/6 mice postweaning (two BALB/c and two C57BL/6 mice per cage). Their cages were also supplemented with two established components of environmental enrichments, namely igloos and cotton swabs that stimulate nest-building activities. Compared with IMS $\mathrm{BALB} / \mathrm{c}$ mice raised in a nonenriched environment, $\mathrm{BALB} / \mathrm{c}$ mice crosshoused with $\mathrm{C} 57 \mathrm{BL} / 6$ mice were far better groomed, and their body weights at $\mathrm{P} 60$ were $20 \%$ higher.

Modified forced swim test. A modified version of the forced swim test (FST) was used, which, after re-exposure to the FST, elicits a state of "learned helplessness" that is sensitive to chronic, but not acute or subacute, antidepressant treatment (Dulawa et al., 2004). Briefly, mice were placed into plastic buckets ( $23 \mathrm{~cm}$ deep and $19 \mathrm{~cm}$ in diameter) filled with $25^{\circ} \mathrm{C}$ water and videotaped for 6 min to monitor the number of passive episodes and their duration (in seconds) as well as the time spent actively swimming. On the following day, mice were re-exposed to the FST for 6 min, and their behavior was recorded as described above. Twenty-four hours after the second FST, mice were killed by rapid decapitation, their brains were removed, and forebrain neocortical tissue was dissected.

Drug treatment. For chronic fluoxetine treatments, mice received the drug dissolved in drinking water $(10 \mathrm{mg} / \mathrm{ml})$ as described previously (Gurevich et al., 2002a). The amount of fluoxetine intake was monitored via daily measurements of water consumption, which revealed an average intake of $16 \mathrm{mg} / \mathrm{kg} / \mathrm{d}$ fluoxetine for adult SFR and IMS mice. Mice treated with fluoxetine between P32 and P61 consumed an average of $7.5 \mathrm{mg} /$ $\mathrm{kg} / \mathrm{d}$ in the first week of treatment, $10 \mathrm{mg} / \mathrm{kg} / \mathrm{d}$ in the second week, 13.5 $\mathrm{mg} / \mathrm{kg} / \mathrm{d}$ in the third week, and $16 \mathrm{mg} / \mathrm{kg} / \mathrm{d}$ in the fourth week. The latter dose has been shown previously to lead to serum levels of fluoxetine in $\mathrm{BALB} / \mathrm{c}$ mice that are equivalent to therapeutic doses used in humans (Dulawa et al., 2004). Mice receiving either adult or adolescent fluoxetine were housed in at least four cages so that animals could be randomly selected from different cages for measurements of basal $5-\mathrm{HT}_{2 \mathrm{C}}$ premRNA editing or behavioral testing followed by measurements of $5-\mathrm{HT}_{2 \mathrm{C}}$ pre-mRNA editing responses.

RNA extraction, real-time reverse transcription- $P C R$, and nucleotide sequencing. Forebrain neocortical tissue was dissected using the mesodiencephalic junction as the anatomic landmark for the caudal border of the forebrain. RNA was extracted using guanidine/cesium chloride ultracentrifugation. Ten micrograms of total RNA were used for first-strand cDNA synthesis using murine moloney leukemia virus reverse transcriptase (USB, Cleveland, OH). Real-time PCRs were performed using the iQ5 Real-Time PCR Detection System (Bio-Rad, Hercules, CA). All reactions were run in triplicate and contained Sybr green (Bio-Rad), which fluoresces when intercalated with DNA. PCR amplification of $5-\mathrm{HT}_{2 \mathrm{C}}$ cDNA was specified by the primer pair 5'-TATTGTGCCCCGTCTGG3'/5'-GAGCACGCAGGTAGTATT-3'. PCR products were gel purified and cloned into the plasmid vector pCRII (Invitrogen, Carlsbad, CA). Single bacterial transformations, plated onto $150 \mathrm{~mm}$ dishes, yielded $>300$ recombinant colonies from which 48 were randomly picked for plasmid DNA extraction and nucleotide sequencing using Sanger's dideoxy chain termination method.

Additional primers were designed to amplify $300 \mathrm{nt}$ fragments near the $\mathrm{N}$ terminus of the $\mathrm{G} \alpha \mathrm{q}$ subunit of G-protein (5'-ACTCTGGAGTCCATCATG-3'/5'-TGTATGGGATCTTGAGCG-3'), the GABA receptor $\alpha 1$ subunit (5'-CATTCTGAGCACACTGTC-3'/5' -AAGGTTGTTTAGCCGGAG-3'), and the early growth response gene 3 (egr-3) ( $5^{\prime}$-ATGACCGGCAAACTCGCC-3'/5-GGCACTCATGAGGCTAAT- ${ }^{\prime}$ ). In all real-time PCR experiments, measurements were made of the number of cycles required to reach the threshold fluorescence intensity [cycle threshold $(\mathrm{Ct})]$. Ct values for each reaction were subtracted from $\mathrm{Ct}$ values for SFR animals that served as a baseline, and the result was referred to as $\Delta \mathrm{Ct}$. Fold changes in gene expression were calculated as $2^{\Delta \mathrm{Ct}}$ to reflect the fact that, under optimal conditions, the amount of PCR product doubles with each amplification cycle. Results were then normalized to those obtained for amplifications of the same cDNA samples using primers designed against $\beta$-actin, which acts as an internal standard, and averaged for each treatment group.

Immunoblotting. Protein was extracted in a buffer containing $250 \mathrm{~mm}$ sodium chloride, 25 mm Tris-HCl, pH 7.5, 5 mм EDTA, pH 8, 1\% Triton $\mathrm{X}-100$, and protease inhibitors. Total protein $(10 \mu \mathrm{g})$ was analyzed by Western blotting using rabbit polyclonal antibodies directed against G $\alpha \mathrm{q} / 11 \alpha$ (1:1000; Chemicon, Temecula, CA) and $\beta$-actin (1:1000; Cell Signaling Technology, Berkeley, MA). Bound antigen was visualized using a peroxidase-conjugated anti-rabbit IgG secondary antibody (KPL, Gaithersburg, MD) in conjunction with enhanced chemiluminescence (ECL) (GE Healthcare, Piscataway, NJ), and optical densities of ECL signals on autoradiograms were then analyzed using NIH Image Analysis software.

\section{Results}

Effect of early life stress on adult behavioral responses to the forced swim test

In the first series of experiments, we compared the behavioral responses of adult SFR and IMS mice to the FST (see Materials and Methods). As shown in Figure 1, IMS mice spent significantly 

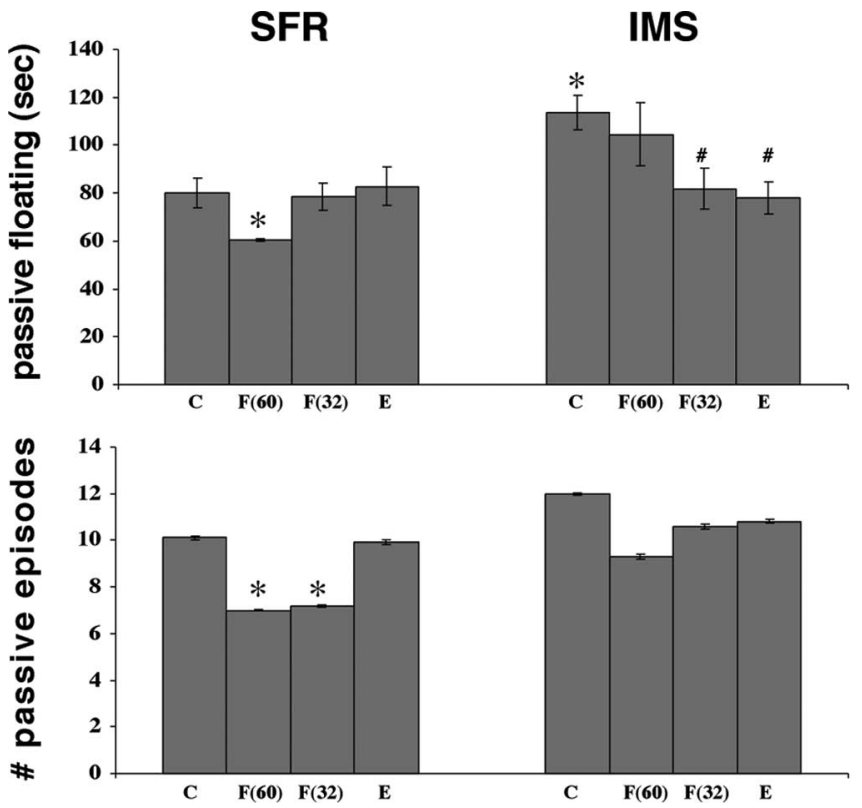

Figure 1. Effect of early life stress (IMS) on behavioral responses to the forced swim test. Total time spent passively floating and number of passive episodes recorded during the second FST exposure of adult nontreated SFR and IMS mice (labeled C), SFR and IMS mice treated with fluoxetine between P60 and P88 [labeled F(60)] or between P32 and P61 [labeled F(32)], or exposed to postweaning environmental enrichment (E). Data represent means $\pm S E M$ of determinations made from 10 to 16 animals per group. Each group was composed of an equal number of male and female mice. Within each group, no significant differences were found in measurements obtained from male and female mice. A one-way ANOVA revealed significant differences $\left(F_{(7,73)}=3.719 ; p=0.0017\right.$ for passive floating time, and $F_{(7,73)}=5.28 ; p<$ 0.0001 for the number of passive episodes) that were resolved post hoc (Tukey-Kramer multiple comparisons) as indicated. ${ }^{*} p<0.05$ compared with SFR controls, and ${ }^{\#} p<0.03$ compared with IMS controls.

more time passively floating compared with SFR controls. Moreover, SFR mice treated chronically with fluoxetine $(16 \mathrm{mg} / \mathrm{kg} / \mathrm{d})$ between P60 and P88 exhibited significantly decreased passive floating time and significantly decreased numbers of passive episodes in the FST compared with nontreated SFR mice. In IMS mice, however, the same treatment with fluoxetine did not significantly alter the behavioral responses to the FST (Fig. 1). Thus, early life stress increases passive behavioral responses to adult FST exposure, and this behavioral phenotype is unaffected by adult fluoxetine treatment.

In additional experiments, SFR and IMS mice were treated with fluoxetine during adolescence (i.e., between P32 and P61), and their behavioral responses to the FST (measured at P61) are shown in Figure 1. In SFR animals, adolescent fluoxetine treatment, like adult fluoxetine treatment, significantly decreased the number of passive episodes, but their total time spent passively floating was not significantly different from corresponding measures obtained from nontreated SFR mice. In IMS mice, however, adolescent fluoxetine treatment led to significantly decreased passive floating time compared with nontreated IMS mice, and these behavioral measures no longer differed from nontreated SFR mice and SFR mice treated with fluoxetine between P32 and P61. In contrast to SFR mice, however, in fluoxetine-treated IMS mice, the total number of passive episodes remained unaltered, suggesting that fluoxetine differentially modulates the behavioral strategies (i.e., reducing the number of passive episodes vs reducing the duration of passive episodes) of SFR and IMS mice to ultimately reduce overall passive behavior.

Additional groups of SFR and IMS mice were raised in an enriched environment (see Materials and Methods). This treatment did not alter the behavioral response of SFR mice to the FST (Fig. 1). In IMS mice, however, this enrichment resulted in significantly decreased time spent passively floating compared with corresponding measures obtained from IMS mice raised in a nonenriched environment, and the behavioral responses of these mice to the FST differed neither from IMS mice treated with fluoxetine during adolescence nor from all groups of SFR mice (Fig. 1). Thus, adolescent fluoxetine treatment and environmental enrichment during adolescence are equally effective in diminishing the elevated passive behavioral responses of IMS mice to the FST, and both treatments reduced the duration of passive episodes but not the total number of these episodes.

\section{Differential effects of postnatal enrichment and fluoxetine on} forebrain neocortical 5- $\mathrm{HT}_{2 \mathrm{C}}$ pre-mRNA editing and $\mathrm{G} \alpha q \mathrm{mRNA}$ and protein expression

We have shown previously that normally raised adult BALB/c mice express predominantly nonedited and $\mathrm{AB}$ sites-edited forebrain neocortical $5-\mathrm{HT}_{2 \mathrm{C}}$ mRNA that encode receptors with the highest sensitivity to serotonin (Englander et al., 2005). We also found that exposure to the FST increased $5-\mathrm{HT}_{2 \mathrm{C}}$ pre-mRNA editing in these mice and that this effect was blocked by chronic fluoxetine treatment during adulthood (Englander et al., 2005). These results pointed to a significant role of stress in modulating $5-\mathrm{HT}_{2 \mathrm{C}}$ pre-mRNA editing phenotypes and suggested the possibility that different $5-\mathrm{HT}_{2 \mathrm{C}}$ pre-mRNA editing phenotypes detected in the forebrain neocortex reflect different behavioral/ emotive states of the animal. To test this, we examined whether early life stress alters basal and stress-induced $5-\mathrm{HT}_{2 \mathrm{C}}$ pre-mRNA editing phenotypes of adult IMS mice and whether the similar behavioral effects of adolescent fluoxetine and postweaning enrichment described in Figure 1 are also accompanied by corresponding changes in $5-\mathrm{HT}_{2 \mathrm{C}}$ pre-mRNA editing.

As shown in Figure $2 A$, compared with SFR mice, adult IMS$\mathrm{BALB} / \mathrm{c}$ mice exhibited a profoundly different basal $5-\mathrm{HT}_{2 \mathrm{C}}$ premRNA editing phenotype. In fact, these mice exhibited significantly increased editing at the A, B, C, and D sites $(p<0.001)$ that led to decreased expression of nonedited and $\mathrm{AB}$ sites-edited $5-\mathrm{HT}_{2 \mathrm{C}}$ mRNA ( $p<0.001$ and $p<0.05$, respectively) and increased expression of ABD- and ABCD-edited mRNA isoforms $(p<0.01)$ (Fig. 2A). This basal editing phenotype was unaltered in IMS mice treated chronically with fluoxetine in adulthood. Hence, in contrast to SFR mice that express predominantly $5-\mathrm{HT}_{2 \mathrm{C}}$ mRNA isoforms that encode receptors with the highest sensitivity to serotonin, $>60 \%$ of edited $5-\mathrm{HT}_{2 \mathrm{C}}$ mRNA expressed in IMS mice encode receptors with reduced function regardless of whether they received fluoxetine in adulthood.

Figure $2 B$ compares the editing phenotypes of adult SFR and IMS mice that were exposed to the FST. Although SFR BALB/c mice exhibited increased editing of $5-\mathrm{HT}_{2 \mathrm{C}}$ pre-mRNA in response to the FST as described previously (Englander et al., 2005), the editing phenotype of IMS-BALB/c mice exposed to the FST remained significantly different when compared with SFR-FST mice (i.e., they still exhibited significantly higher editing at $A, B$, $\mathrm{C}$, and D sites) [ $p<0.001$ (A, B, and D sites); $p<0.02$ (C site)], lower expression of nonedited mRNA $(p<0.001)$, and significantly higher expression of ABCD-edited $(p<0.05)$ and ABDedited $(p<0.01)$ mRNA (Fig. $2 B)$.

A statistical comparison between basal (Fig. 2A) and FSTinduced (Fig. $2 \mathrm{~B}$ ) $5-\mathrm{HT}_{2 \mathrm{C}}$ pre-mRNA editing also revealed that, although the percentages of major edited $5-\mathrm{HT}_{2 \mathrm{C}}$ mRNA isoforms expressed in IMS-FST mice with and without adult fluox- 
etine treatment did not differ from the corresponding basal editing phenotypes, C site editing (calculated for all sequences) was significantly $(p<0.05)$ higher in IMS mice exposed to the FST but unaltered in IMS mice treated with fluoxetine [IMS (basal), $17.5 \pm 1.5 \%$; IMS/fluoxetine (basal), $20.96 \pm 2.2 \%$; IMS-FST, $30.8 \pm$ 3.3\%; IMS/fluoxetine/FST, $21.7 \pm 2.7 \%$ ]. In IMS-FST mice, increased $\mathrm{C}$ site editing was primarily attributable to the expression of the $\mathrm{A}(\mathrm{B}) \mathrm{C}$-edited mRNA isoform, which represented $\sim 8 \%$ of their edited mRNA isoforms but was never detected at baseline or after adult fluoxetine treatment. Thus, adult stress exposure of IMS $\mathrm{BALB} / \mathrm{c}$ mice further increased $\mathrm{C}$ site editing to increase the pool of mRNAs encoding receptors with reduced function, and this effect was blocked by adult fluoxetine treatment.

Finally, although both adolescent fluoxetine and postweaning enrichment exerted similar behavioral effects in the FST, $5-\mathrm{HT}_{2 \mathrm{C}}$ pre-mRNA editing phenotypes were not equally modulated by these treatments (Fig. 3). In SFR mice exposed to postweaning enrichment, neither the basal editing phenotype nor the editing phenotype after FST exposure differed from corresponding measures of SFR controls (Fig. $3 A, B$ ). In contrast, adolescent fluoxetine treatment of SFR mice led to an approximately twofold increase in basal A, B, C, and D site editing $\left(\right.$ ANOVA; $F_{(7,24)}=23.93, p<0.0001$; post hoc, $p<0.01$ for all four editing sites) resulting in decreased expression of nonedited mRNA and increased expression of $\mathrm{ABD}$ and $\mathrm{ABCD}$ sites-edited mRNA (ANOVA; $F_{(11,32)}=57.84 ; p<0.0001 ;$ post hoc, $p<0.001$ for the nonedited isoform, $p<0.05$ for ABD- and ABCD-edited isoforms) (Fig. $3 A$ ). The editing phenotype remained unaltered after FST exposure. In fact, after FST exposure, editing phenotypes of mice exposed to postweaning enrichment or adolescent fluoxetine did not differ from FST-exposed SFR controls (Fig. 3B).

The basal 5- $\mathrm{HT}_{2 \mathrm{C}}$ pre-mRNA editing phenotype of IMS mice raised in the enriched environment was also indistinguishable from the basal editing phenotype determined for nontreated IMS mice (Fig. 3C). The basal editing phenotype of IMS mice treated with fluoxetine during adolescence, however, differed significantly from IMS controls (ANOVA; $F_{(11,56)}=35.96 ; p<0.0001$ for editing combinations, and $F_{(13,68)}=127.98, p<0.0001$ for editing sites). Post hoc Tukey-Kramer multiple comparisons revealed that fluoxetine-treated IMS mice exhibited significantly increased expression of nonedited $5-\mathrm{HT}_{2 \mathrm{C}}$ mRNA $(p<0.001)$, and editing of the A, B, and D sites was significantly decreased $(p<0.01)$ compared with nontreated IMS mice and IMS mice raised in the enriched environment (Fig. $3 C$ ). Thus, in contrast to the effect of adolescent fluoxetine in SFR mice with low basal editing (where fluoxetine leads to increased basal editing), the same treatment decreased basal editing in IMS mice with high basal editing.

Within the groups of FST-exposed IMS mice, differences in the percentages of major edited isoforms revealed by ANOVA $\left(F_{(11,60)}=36.27 ; p<0.0001\right)$ were resolved post hoc only for
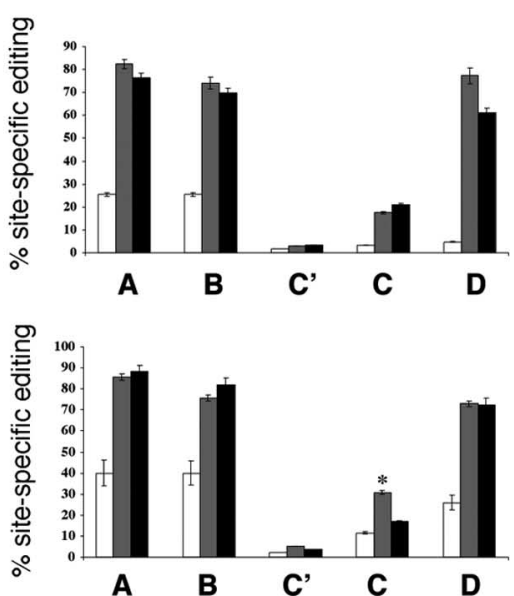

A

Figure 2. Comparison of basal and FST-induced 5-HT 2 c pre-mRNA editing between SFR mice, drug-naive IMS mice, and IMS treated with fluoxetine between P60 and P88 [IMS-F(P60)]. A, Basal editing phenotype. $B$, Editing phenotype after exposure of determinations made from 48 sequences per animal and five animals per group (totaling 1440 sequences of 30 animals).

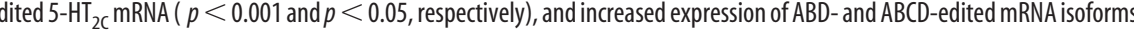
政 compared with IMS controls. ${ }^{*} p<0.05$ compared with SFR and IMS-F(P60) mice. NE, Nonedited.

FST-exposed mice treated with fluoxetine between P32 and P61 (Fig. 3D). These mice exhibited significantly increased expression of the nonedited isoform $(p<0.01$ compared with nontreated IMS mice, and $p<0.05$ compared with IMS mice raised in the enriched environment). In addition, significant differences in the percentages of site-specific editing (Fig. 3D) (ANOVA; $F_{(14,75)}=$ 140.63; $p<0.0001)$ were found only for fluoxetine-treated mice that had lower A and B $(p<0.05)$ as well as D site editing $(p<$ $0.01)$. Finally, no significant differences were found between basal (Fig. 3C) and FST-induced editing phenotypes of fluoxetine-treated IMS (Fig. 3D), indicating that adolescent fluoxetine treatment not only decreased basal $5-\mathrm{HT}_{2 \mathrm{C}}$ pre-mRNA editing but also blocked increased editing responses to adult stress.

A comparison between results obtained from the groups of SFR (Fig. $3 A, B$ ) and IMS (Fig. 3C,D) mice exposed to either postweaning enrichment or adolescent fluoxetine revealed that, regardless of treatment, editing of $5-\mathrm{HT}_{2 \mathrm{C}}$ pre-mRNA editing was always significantly higher in IMS mice. For example, FSTexposed IMS mice treated with fluoxetine or subjected to postweaning enrichment showed significantly higher A, B, and D site editing compared with corresponding groups of SFR mice (ANOVA; $F_{(15,44)}=31.040, p<0.0001$; post hoc, $p<0.05$ for A, $\mathrm{B}$, and $\mathrm{D}$ site editing of fluoxetine-treated mice and $p<0.001$ for $\mathrm{A}, \mathrm{B}$, and $\mathrm{D}$ site editing of mice raised in the enriched environment).

In summary, in both SFR and IMS mice, postweaning environmental enrichment did not affect basal or FST-induced $5-\mathrm{HT}_{2 \mathrm{C}}$ pre-mRNA editing phenotypes. Adolescent fluoxetine treatment, however, had opposite effects on the basal $5-\mathrm{HT}_{2 \mathrm{C}}$ pre-mRNA editing phenotypes of SFR (increased editing) and IMS (decreased editing). Nevertheless, regardless of these treat- 
A

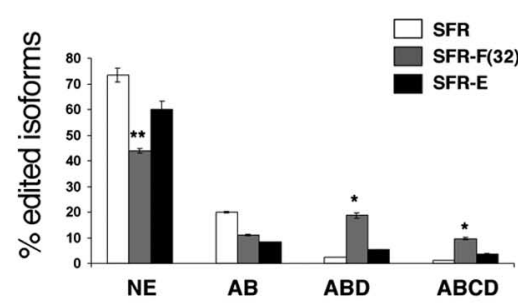

B

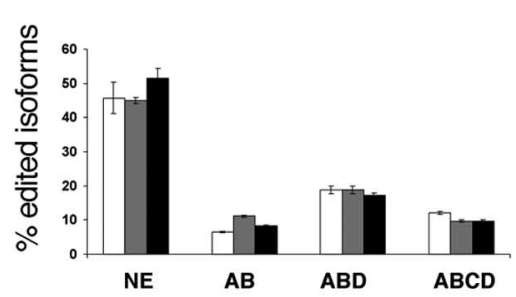

C

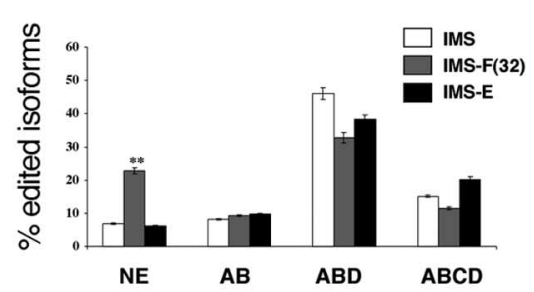

D

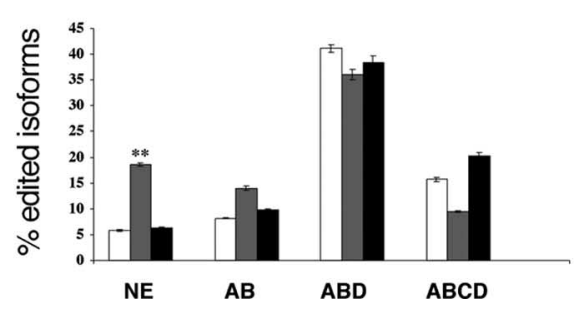

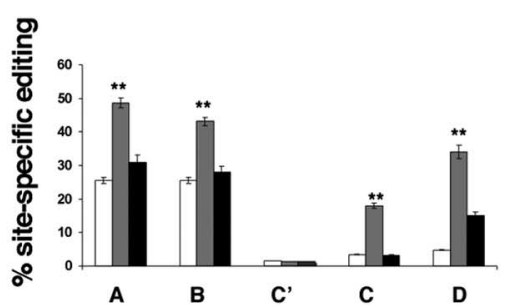
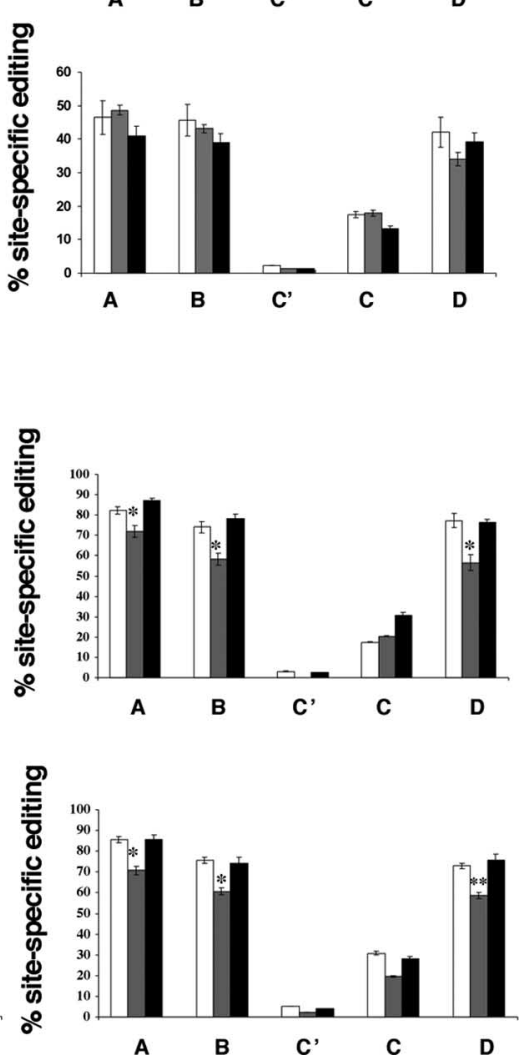

Figure 3. Effect of adolescent fluoxetine $[\mathrm{F}(32)]$ and postweaning enrichment on $5-\mathrm{HT}_{2 C}$ pre-mRNA editing in SFR and IMS $\mathrm{BALB} / \mathrm{c}$ mice. Basal $(\boldsymbol{A})$ and FST-induced $(\boldsymbol{B})$ editing phenotypes of SFR mice. Basal $(\boldsymbol{C})$ and FST-induced $(\boldsymbol{D})$ editing phenotype of IMS mice. In SFR mice, fluoxetine treatment resulted in significantly increased basal editing, and this editing was unaltered after FST exposure. ${ }^{* *} p<0.01 ;{ }^{*} p<0.05$ compared with SFR controls. Enrichment had no effect on basal editing and did not protect from increased editing in response to FST exposure. In IMS mice, enrichment affected neither basal nor FST-induced editing phenotypes, but fluoxetine decreased basal editing of $A, B$, and $D$ sites (leading to increased nonedited $m R N A$ ) and protected from increased editing responses to the FST. ${ }^{* *} p<0.001 ;{ }^{*} p<0.01$ compared with IMS controls. Data represent means \pm SEM of determinations made from 48 sequences per animal and five animals per group. NE, Nonedited.

ments, $5-\mathrm{HT}_{2 \mathrm{C}}$ pre-mRNA editing was always significantly higher in IMS compared with SFR mice.

Results of real-time reverse transcription (RT)-PCR experiments revealed nearly identical cytoplasmic $5-\mathrm{HT}_{2 \mathrm{C}}$ mRNA levels in SFR mice, nontreated IMS mice, and IMS mice treated with fluoxetine between P60 and P88 or between P32 and P61 (threshold cycles were 19.4 \pm 0.6, 19.2 $\pm 1.1,19.0 \pm 0.9$, and $19.2 \pm 0.8$, respectively). Hence, the changes in editing described above occurred in the absence of changes in cytoplasmic $5-\mathrm{HT}_{2 \mathrm{C}}$ mRNA levels. However, an initial cDNA microarray screen pointed to differences in levels of mRNA encoding the $\mathrm{G} \alpha \mathrm{q}$ subunit of G-protein in these samples. $\mathrm{G} \alpha \mathrm{q}$ couples to $5-\mathrm{HT}_{2 \mathrm{~A} / 2 \mathrm{C}}$ receptors, and increased editing of $5-\mathrm{HT}_{2 \mathrm{C}}$ receptors decreases this coupling efficiency (Niswender et al., 1999; Wang et al., 2000). Results of independent real-time RT-PCR experiments (Table 1) revealed that, compared with nontreated SFR mice, G $\alpha$ q mRNA levels were neither significantly altered in fluoxetine-treated SFR mice nor in SFR mice exposed to postweaning enrichment. In non- treated IMS mice, however, G $\alpha \mathrm{q}$ mRNA was significantly (approximately twofold) increased $(p<0.001)$ compared with SFR controls, and IMS mice raised in the enriched environment also exhibited increased levels of $\mathrm{G} \alpha \mathrm{q}$ mRNA, although this increase did not reach significance. In contrast, IMS mice treated with fluoxetine between P60 and P88 exhibited significantly decreased $\mathrm{G} \alpha \mathrm{q}$ mRNA levels compared with SFR controls ( $\sim 2.5$-fold; $p<$ 0.05 ), and this decrease was even larger in IMS mice treated with fluoxetine between P32 and P61 (approximately fourfold; $p<$ $0.01)$.

The microarray screen revealed additional genes with altered expression in IMS mice treated with fluoxetine, and real-time RT-PCR experiments confirmed that mRNA encoding the transcription factor egr-3 was significantly increased in SFR mice treated with fluoxetine between P32 and P61 ( $p<$ $0.001)$ but decreased in IMS mice that received the same treatment $(p<0.02)$ (Table 1). Furthermore, IMS mice treated with fluoxetine between P32 and P61 exhibited significantly decreased expression of mRNA encoding the $\alpha 1$ subunit of the $\mathrm{GABA}_{\mathrm{A}}$ receptor $(p<0.01)$, but SFR mice raised in the enriched environment exhibited increased expression of this receptor subunit $(p<0.01)$. Hence, early life stress, postweaning environmental enrichment, and fluoxetine treatment exert differential effects on forebrain neocortical gene expression in SFR and IMS mice (Table 1). The changes (increased or decreased expression) in G $\alpha \mathrm{q}$, egr-3, or $\mathrm{GABA}_{\mathrm{A}} \alpha 1$ mRNA expression differ for each treatment group. Thus, the different $\mathrm{G} \alpha \mathrm{q}$ expression levels measured in this study are unlikely to be a result of general differences in RNA stability and/or turnover between the different groups of mice. Moreover, the differences in G $\alpha \mathrm{q}$ mRNA levels shown in Table 1 could also be confirmed with measurements of forebrain neocortical $\mathrm{G} \alpha \mathrm{q}$ protein levels (Fig. 4). IMS BALB/c mice expressed $63 \pm 12.9 \%$ more $\mathrm{G} \alpha q$ protein compared with SFR controls, and the $\mathrm{G} \alpha \mathrm{q}$ protein levels in IMS mice raised in the enriched environment were $33 \pm 5.7 \%$ higher. In fluoxetine-treated IMS mice, however, G $\alpha$ q protein levels were $25 \pm 5.1 \%$ lower compared with SFR controls, and more than twofold lower compared with nontreated IMS mice.

\section{Discussion}

The present study shows that, in the inbred strain BALB/c, early life stress increased expression of mRNA encoding $5-\mathrm{HT}_{2 \mathrm{C}}$ receptor isoforms with reduced sensitivity to serotonin in adulthood. This is achieved posttranscriptionally by RNA editing. Moreover, early life stress and genetic vulnerability act synergistically to produce persistent changes in $5-\mathrm{HT}_{2 \mathrm{C}}$ pre-mRNA editing that are 
Table 1. Effect of chronic fluoxetine and environmental enrichment on forebrain neocortical gene expression in SFR and IMS mice ${ }^{a}$

\begin{tabular}{llll}
\hline & $G \alpha q$ & egr-3 & $\mathrm{GABA}_{\mathrm{A}} \alpha 1$ \\
\hline SFR-F(P60) & $0.87 \pm 0.16$ & $0.57 \pm 0.12$ & $0.74 \pm 0.12$ \\
SFR-F(P28) & $1.35 \pm 0.21$ & $2.24 \pm 0.43^{* * *}$ & $1.20 \pm 0.16$ \\
SFR-E & $1.26 \pm 0.16$ & $1.08 \pm 0.15$ & $1.54 \pm 0.07^{* *}$ \\
IMS & $2.43 \pm 0.42^{* * *}$ & $0.82 \pm 0.29$ & $1.11 \pm 0.31$ \\
IMS-F(P60) & $0.38 \pm 0.12^{*}$ & $0.55 \pm 0.13$ & $0.96 \pm 0.14$ \\
IMS-F(P28) & $0.24 \pm 0.07^{* *}$ & $0.22 \pm 0.06^{* *}$ & $0.53 \pm 0.07^{* *}$ \\
IMS-E & $1.34 \pm 0.17$ & $0.67 \pm 0.25$ & $0.91 \pm 0.21$ \\
\hline
\end{tabular}

${ }^{a}$ Data are expressed as fold-change relative to SFR controls and represent mean \pm SEM of determinations made from five to eight animals per group. ${ }^{* * *} p<0.001$; ${ }^{* *} p<0.01 ;{ }^{*} p<0.05$ (ANOVA; post hoc Tukey-Kramer multiple comparisons).
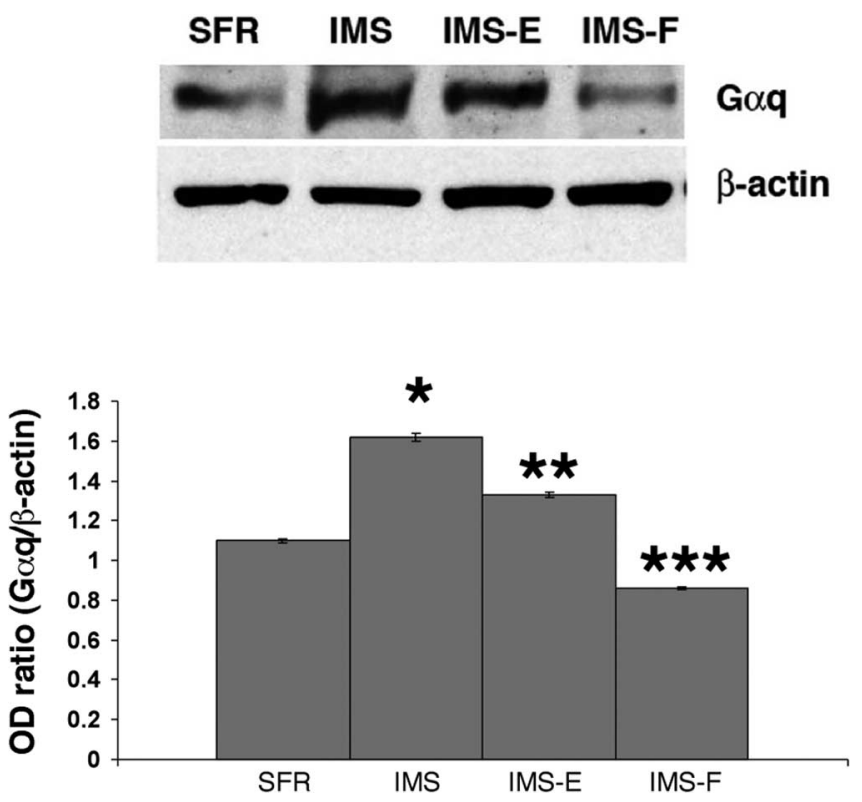

Figure 4. Immunoblot analysis of $\mathrm{G} \alpha q$ protein expression in IMS BALB/c mice exposed to either enriched environment or fluoxetine. Ten micrograms of total protein, extracted from forebrain neocortex of adult SFR controls, nontreated IMS mice (IMS), IMS mice raised in the enriched environment (IMS-E), and IMS mice treated with fluoxetine between P60 and P88 (IMS-F), were loaded onto each lane. Optical densities of ECL signals on autoradiograms were measured using NIH Image software. Differences in the expression of $\mathrm{G} \alpha \mathrm{q}$ immunoreactivity relative to the expression of $\beta$-actin were determined from measurements obtained from five animals per group. Statistical differences (ANOVA; $\left.F_{(3,13)}=18.33 ; p<0.0001\right)$ were resolved post hoc using Tukey-Kramer multiple comparisons tests. ${ }^{*} p<0.01$ compared with SFR; ${ }^{* *} p<0.01$ compared with IMS; ${ }^{* *} p<0.001$ compared with IMS.

more severe compared with those previously reported to result from adult stress exposure alone (Englander et al., 2005).

Early life stress of BALB/c mice also altered the effectiveness of chronic fluoxetine treatment in ameliorating behavioral and $5-\mathrm{HT}_{2 \mathrm{C}}$ pre-mRNA editing responses to adult stress. Consistent with the results of Dulawa et al. (2004), chronic fluoxetine treatment of adult SFR mice significantly decreased their passive behavioral response to the FST, and chronic adolescent fluoxetine treatment of these mice exerted a similar, albeit somewhat weaker effect (Fig. 1). In IMS BALB/c mice, however, chronic fluoxetine administered during adulthood did not significantly alter the behavioral response to the FST, and only fluoxetine administered during adolescence significantly decreased their passive behavioral responses to the FST. In this regard, it is of interest to note that reduced responsiveness to antidepressant treatment has also been reported for adult human subjects with a history of adverse early life events (Nemeroff et al., 2003). Moreover, in the present study, SFR and IMS BALB/c mice exhibited substantial differences in the modulation of $5-\mathrm{HT}_{2 \mathrm{C}}$ pre-mRNA editing phenotypes in response to stress and adult fluoxetine. Compared with SFR mice, IMS mice exhibited a robust increase in basal $5-\mathrm{HT}_{2 \mathrm{C}}$ pre-mRNA editing in the adult forebrain neocortex. In fact, although SFR mice exposed to the FST exhibited increased 5- $\mathrm{HT}_{2 \mathrm{C}}$ pre-mRNA editing, in FST-exposed IMS mice, editing of 5- $\mathrm{HT}_{2 \mathrm{C}}$ pre-mRNA was still significantly higher.

We have shown previously that adult fluoxetine treatment blocked the increased editing responses to adult FST exposure in normally raised BALB/c mice (Englander et al., 2005). The present study revealed, however, that although adult fluoxetine treatment of IMS BALB/c mice also blocked the increase in C site editing that occurred in response to FST exposure of nontreated IMS mice, it did not alter the abnormally increased basal $5-\mathrm{HT}_{2 \mathrm{C}}$ pre-mRNA editing phenotype. However, adolescent fluoxetine treatment of IMS mice diminished the magnitude of their increased basal $5-\mathrm{HT}_{2 \mathrm{C}}$ pre-mRNA and also blocked $5-\mathrm{HT}_{2 \mathrm{C}}$ premRNA editing responses to adult stress. This suggests that fluoxetine can modulate the $5-\mathrm{HT}_{2 \mathrm{C}}$ pre-mRNA editing phenotype of IMS mice only when the drug is administered before the establishment of the adult editing phenotype.

Our data also show that, although postweaning environmental enrichment and adolescent fluoxetine treatment ameliorated the heightened passive behavioral responses of IMS BALB/c mice to the FST to a similar extent, only adolescent fluoxetine treatment led to decreased editing of $5-\mathrm{HT}_{2 \mathrm{C}}$ pre-mRNA in these mice. Moreover, in SFR mice, postweaning enrichment affected neither the behavioral responses to the FST nor the $5-\mathrm{HT}_{2 \mathrm{C}}$ premRNA editing phenotype, and fluoxetine decreased passive behavioral responses to the FST but increased $5-\mathrm{HT}_{2 \mathrm{C}}$ pre-mRNA editing in these mice. These differential effects of enrichment and adolescent fluoxetine on the behavioral responses to stress and corresponding $5-\mathrm{HT}_{2 \mathrm{C}}$ pre-mRNA editing phenotypes in SFR and IMS BALB/c mice illustrate clearly that $5-\mathrm{HT}_{2 \mathrm{C}}$ receptor editing per se cannot be a major modulator of the behavioral (affective) state of the animal. Hence, it is unlikely that the increased $5-\mathrm{HT}_{2 \mathrm{C}}$ pre-mRNA editing previously reported for depressed suicide victims (Gurevich et al., 2002a) is the cause of depressed mood. Rather, our data suggest the possibility that the extent of alteration in $5-\mathrm{HT}_{2 \mathrm{C}}$ receptor function predicted to result from significantly altered $5-\mathrm{HT}_{2 \mathrm{C}}$ pre-mRNA editing is ultimately determined by the extent to which changes in $\mathrm{G} \alpha \mathrm{q}$ expression levels can compensate for such changes in editing. In fact, the present study shows that IMS mice with increased editing of $5-\mathrm{HT}_{2 \mathrm{C}}$ pre-mRNA also exhibited increased $\mathrm{G} \alpha \mathrm{q}$ expression. Because $5-\mathrm{HT}_{2 \mathrm{C}}$ receptor stimulation activates $\mathrm{G} \alpha \mathrm{q}$-stimulated signal transduction pathways, and because $5-\mathrm{HT}_{2 \mathrm{C}}$ pre-mRNA editing is increased in response to sustained stimulation of $5-\mathrm{HT}_{2 \mathrm{C}}$ receptors to encode receptors with decreased G-protein-coupling efficiencies (Gurevich et al., 2002b), these findings suggest that a persistent increase in editing elicits a compensatory increase in $\mathrm{G} \alpha \mathrm{q}$ expression to maintain homeostatic signaling through 5- $\mathrm{HT}_{2 \mathrm{C}}$ receptors. Indeed, we show here that vehicle-treated IMS mice or IMS mice raised in the enriched environment exhibit the highest $\mathrm{G} \alpha \mathrm{q}$ expression levels and highest basal and FST-induced $5-\mathrm{HT}_{2 \mathrm{C}}$ pre-mRNA editing. IMS mice treated with fluoxetine during adulthood exhibit an approximately twofold decrease in G $\alpha \mathrm{q}$ mRNA expression compared with SFR controls, and these mice do not show an increase in editing in response to adult stress. IMS mice treated with fluoxetine during adolescence exhibit an approximately fourfold decrease in G $\alpha$ q expression and also exhibit significantly decreased basal $5-\mathrm{HT}_{2 \mathrm{C}}$ pre-mRNA ed- 
iting. Thus, in our study, a reversal of the increased basal $5-\mathrm{HT}_{2 \mathrm{C}}$ pre-mRNA editing in IMS mice was detected only in those mice that exhibited the largest decrease in $\mathrm{G} \alpha \mathrm{q}$ expression levels.

Finally, although SFR mice also exhibit increased editing in response to either stress or fluoxetine, the changes in editing were not accompanied by significant changes in $\mathrm{G} \alpha \mathrm{q}$ expression levels. This finding indicates that possible compensatory responses mediated at the level of $\mathrm{G} \alpha \mathrm{q}$ expression occur in only mice with persistently altered $5-\mathrm{HT}_{2}$ pre-mRNA editing phenotypes (IMS mice) and not in mice that exhibit increased editing responses to acute stress exposure or fluoxetine treatment (i.e., SFR mice exhibiting physiologically normal editing responses). Nevertheless, the a priori assumption that alterations in $5-\mathrm{HT}_{2 \mathrm{C}}$ pre-mRNA editing in vivo lead to those alterations in $5-\mathrm{HT}_{2 \mathrm{C}}$ receptor function that are predicted from the pharmacological properties of cloned receptor isoforms expressed in cultured cells is challenged by our finding that persistently altered editing can occur along with altered $\mathrm{G} \alpha \mathrm{q}$ expression.

An alternative explanation for the present finding of altered $\mathrm{G} \alpha \mathrm{q}$ expression in IMS BALB/c mice could be that G $\alpha \mathrm{q}$ activation itself plays a role in modulating $5-\mathrm{HT}_{2 \mathrm{C}}$ pre-mRNA editing. Although studies on the regulation of nuclear pre-mRNA editing are complicated by the fact that the mechanisms by which adenosine deaminases acting on RNA (ADAR) catalyze the deamination of adenosines are essentially unknown (Bass, 2002), it is relevant to note that $\mathrm{G} \alpha \mathrm{q}$ activates phospholipase $\mathrm{C}$, which in turn generates inositol trisphosphate that can be further phosphorylated to inositol hexakisphosphate (IP6). Interestingly, the crystal structure of one of the editing enzymes that act on $5-\mathrm{HT}_{2 \mathrm{C}}$ pre-mRNA, ADAR2, revealed that IP6 is buried within the enzyme core where it is necessary and essential for proper protein folding and catalytic activity (Macbeth et al., 2005). Nevertheless, despite previous speculation that signaling through $5-\mathrm{HT}_{2 \mathrm{C}}$ receptors may play a role in editing of $5-\mathrm{HT}_{2 \mathrm{C}}$ pre-mRNA (Gurevich et al., 2002b; Macbeth et al., 2005), a mechanistic link between receptor-mediated, G $\alpha$ q-stimulated activation of phospholipase $\mathrm{C}$ and $5-\mathrm{HT}_{2 \mathrm{C}}$ pre-mRNA editing remains to be established.

In summary, in the stress-susceptible strain BALB/c, early life stress significantly altered the adult $5-\mathrm{HT}_{2 \mathrm{C}}$ pre-mRNA phenotype and rendered behavioral responses to adult stress resistant to adult fluoxetine treatment. Although postweaning enrichment and adolescent fluoxetine treatment exert significant behavioral effects in an adult stress paradigm, their effects on $5-\mathrm{HT}_{2 \mathrm{C}}$ premRNA editing and G $\alpha \mathrm{q}$ expression differ. The finding that significant changes in $5-\mathrm{HT}_{2 \mathrm{C}}$ pre-mRNA editing phenotypes of IMS mice occur together with possibly compensatory changes in $\mathrm{G} \alpha \mathrm{q}$ expression could explain why changes in behavioral phenotypes do not correlate with corresponding changes in $5-\mathrm{HT}_{2 \mathrm{C}}$ pre-mRNA editing phenotypes.

\section{References}

Bass BL (2002) RNA editing by adenosine deaminases that act on RNA. Annu Rev Biochem 71:817-846.
Belzung C, Griebel G (2001) Measuring normal and pathological anxietylike behaviors in mice: a review. Behav Brain Res 125:141-149.

Burns C, Chu H, Rueter S, Hutchinson LK, Canton H, Sanders-Bush E, Emeson RB (1997) Regulation of serotonin-2C receptor G-protein coupling by RNA editing. Nature 387:303-308.

Caspi A, Sugden K, Moffitt TE, Taylor A, Craig IW, Harrington H, McClay J, Mill J, Martin J, Braithwaite A, Poulton R (2003) Influence of life stress on depression: moderation by a polymorphism in the 5-HTT gene. Science 301:386-389.

Dulawa S, Holick KA, Gundersen B, Hen R (2004) Effects of chronic fluoxetine in animal models of anxiety and depression. Neuropsychopharmacol 29:1321-1330.

Englander MT, Dulawa S, Bhansali P, Schmauss C (2005) How stress and fluoxetine modulate serotonin $2 \mathrm{C}$ receptor pre-mRNA editing. J Neurosci 25:648-651.

Gurevich I, Tamir H, Arango V, Dwork A, Mann JJ, Schmauss C (2002a) Altered editing of serotonin $2 \mathrm{C}$ receptor pre-mRNA in the prefrontal cortex of depressed suicide victims. Neuron 43:349-356.

Gurevich I, Englander MT, Adlersberg M, Siegal N, Schmauss C (2002b) Modulation of serotonin $2 \mathrm{C}$ receptor editing by sustained changes in serotonergic neurotransmission. J Neurosci 22:10529-10532.

Holmes A, le Guisquet AM, Vogel E, Millstein RA, Lerman S, Belzung C (2005) Early life genetic, epigenetic and environmental factors shaping emotionality in rodents. Neurosci Behav Rev 29:1335-1346.

Kendler KS, Kuhn JW, Prescott CA (2004) Childhood sexual abuse, stressful life events and risk factors for major depression in women. Psychol Med 34:1475-1482.

Macbeth MR, Schubert HL, VanDemark AP, Lingam AT, Hill CP, Bass BL (2005) Inositol hexakisphosphate is bound in the ADAR2 core and required for RNA editing. Science 309:1534-1539.

Nemeroff CB, Heim CM, Thase ME, Klein DN, Rush AJ, Schatzberg AF, Ninan PT, McCullough JP, Weiss PM, Dunner DL, Rothbaum BO, Kornstein S, Keitner G, Keller MB (2003) Differential responses to psychotherapy versus pharmacotherapy in patients with chronic forms of major depression and childhood trauma. Proc Natl Acad Sci USA 100:14293-14296.

Niswender C, Copeland SC, Herrick-Davis K, Emeson RB, Sanders-Bush E (1999) RNA editing of the human serotonin 5-hydroxytryptamine 2C receptor silences constitutive activity. J Biol Chem 274:9472-9478.

Penza KM, Heim C, Nemeroff CB (2003) Neurobiological effects of childhood abuse: implications for the pathophysiology of depression and anxiety. Arch Womens Mental Health 6:15-22.

Plotsky PM, Meaney MJ (1993) Early postnatal experience alters hypothalamic corticotropin-releasing factor (CRF) mRNA, median eminence CRF content and stress-induced release in adult brain. Brain Res Mol Brain Res 18:195-200.

Roth BL, Willins DL, Kristiansen K, Kroetze WK (1998) 5-hydroxytryptamine $_{2}$-family receptors (5-hydroxytryptamine ${ }_{2 \mathrm{~A}}$, 5-hydroxytryptamine ${ }_{2 \mathrm{~B}}$, 5-hydroxytryptamine ${ }_{2 C}$ ): where structure meets function. Pharmacol Ther 79:231-257.

Tang X, Orchard SM, Sanford LD (2002) Home cage activity and behavioral performance in inbred and hybrid mice. Behav Brain Res 136:555-569.

Wang Q, O’Brien P, Chen C-X, Cho D-SC, Murray JM, Nishikura K (2000) Altered $\mathrm{G}$ protein-coupling functions of RNA editing isoform and splicing variant serotonin 2C receptors. J Neurochem 74:1290-1300.

Zhang X, Beaulieu J-M, Sotnikova TD, Gainetdinov RR, Caron MG (2004) Tryptophan hydroxylase-2 controls brain serotonin synthesis. Science 305:217. 